\title{
Determination of colour value of jaggery based biscuits stored under ambient temperature using hunter colour lab
}

\author{
Jitendra Kumar' ${ }^{1}$ S. K. Goyal* and Durga Shankar Bunkar ${ }^{2}$ \\ Department of Agricultural Engineering, Institute of Agricultural Sciences, BHU, Varanasi (U.P.) India
}

(Email:skgoyal@bhu.ac.in)

\begin{abstract}
To overcome the problems of excessive consumption of white sugar, attempts are being made to find out alternate sweeteners preferably from sugarcane, which are less harmful. A study was conducted to develop jaggery based biscuits using scientific technology to evaluate the quality and acceptance of fresh as well as stored samples. Hunter colour lab was used to determine of colouring properties of fresh and stored samples. Jaggery based biscuits were prepared using different levels of jaggery. Ingredients used in manufacturing of biscuits were of 40,50 and $60 \%$ Jaggery with control (372 g sugar). The other ingredients were in same proportions viz., wheat flour $1000 \mathrm{~g}$, HVO $400 \mathrm{~g}$, WMP $31.15 \mathrm{~g}$, baking powder $10.90 \mathrm{~g}$, salt $7.8 \mathrm{~g}$, TBHQ $0.03125 \mathrm{~g}$, GMS $17.57 \mathrm{~g}$ and 02 eggs. The finished biscuit samples of $300 \mathrm{~g}$ were packed in HDPE and combination of film (CF) of metalized polystyrene pouches for storage studies at ambient condition. Colour measurement of control and jaggery based biscuits was carried out by using Hunter Lab. Colour value was measured after 60 and 120 days for all four samples. L value was found decreased by increasing the levels of jaggery. The L values, which indicates the lightness decreased due to dark colour of jaggery (L value decreased from 53.32 to 42.43 as a result of jaggery incorporation). L value of colour of the control sample prepared by sugar incorporation was 53.32 because of incorporation of other ingredients and high temperature for baking which caused the browning and caramelization. However, the effect of ambient temperature storage significantly increases "L", "a" and "b" value. All four samples (control, $40 \%, 50 \%$ and $60 \%$ jaggery biscuits) were found to have positive "a" values as $9.42,9.98$, 11.09 and 11.60, respectively. During ambient temperature storage, the value of "a" was found to have increased for all four samples packed in HDPE and CF. However, the effect of ambient temperature storage significantly increases "a" value. The colour change observed during 120 days storage was due to additional development of little brown/red colour. The "b" values were found 20.26, 19.74, 19.55 and 19.15, respectively for biscuit samples (control, 40,50 and $60 \%$ jaggery biscuits). Very little difference was noticed in the values of "b" for all samples. Different packaging materials did not significantly affect the "L", "a" and "b" value.
\end{abstract}

Key Words : Biscuits, Colour, Hunter lab, Jaggery, Storage

View Point Article : Kumar, Jitendra, Goyal, S.K. and Bunkar, Durga Shankar (2021). Determination of colour value of jaggery based biscuits stored under ambient temperature using hunter colour lab. Internat. J. agric. Sci., 17 (2) : 586-593, DOI:10.15740/HAS/IJAS/17.2/ 586-593. Copyright@2021: Hind Agri-Horticultural Society.

Article History : Received : 22.03.2021; Revised : 26.03.2021; Accepted : 04.04.2021

\footnotetext{
* Author for correspondence :

${ }^{1}$ SDJPG College Chnadeshwar, Azamgarh (U.P.) India (Email: jitendrakumar2007@gmail.com)

${ }^{2}$ Department of Dairy Science and Food Technology, Institute of Agricultural Sciences, BHU, Varanasi (U.P.) India (Email: dsbunkar@bhu.ac.in)
} 